\title{
CITOTOXICIDADE DE LÍQUIDOS IÔNICOS IMIDAZÓLICOS EM CÉLULAS-TRONCO MESENQUIMAIS DO CORDÃO UMBILICAL HUMANO
}

\author{
Wyndly Daniel Cardoso Gaião ${ }^{1 *}$, Deborah Tielle de Oliveira Fortes ${ }^{1}$, Juliana Pereira de Aguiar ${ }^{1}$, Márcia Bezerra da \\ Silva ${ }^{1}$, Paloma Lys de Medeiros ${ }^{2}$, Cláudio Gabriel Rodrigues ${ }^{1}$, Dijanah Cota Machado ${ }^{1}$ \\ ${ }^{1}$ Laboratório de Biofísica das Membranas e Células-Tronco Dr. Oleg Krasilnikov, UFPE \\ ${ }^{2}$ Laboratório de Cultura de Tecidos (LCT-DHE), UFPE \\ *wyndly@hotmail.com
}

\section{INTRODUÇÃO}

Os líquidos iônicos (Lls) são sais formados por cátions orgânicos e â nions orgânicos ou inorgânicos de diferentes tamanhos. A pressão ambiente, os Lls possuem ponto de fusão inferior a $100^{\circ} \mathrm{C}$, portanto, constituem uma classe promissora de solventes (JING et al, 2016). Apresentam propriedades como baixa volatilidade, baixa inflamabilidade, estabilidade térmica e solubilidade em água (BATES et al., 2002). Devido a estas características, os Lls têm gerado grande interesse tanto a nível industrial (PLECHKOVA, 2008) como também na comunidade científica (CVJETKO et al., 2012). Os LIs surgiram a partir do desenvolvimento da Química Verde ("Green Chemistry"), que preconiza a amenização de danos ambientais, com o desenvolvimento de tecnologias limpas (ANATAS et al., 2002). A utilização de culturas de células permite avaliar o potencial de citotoxicidade desses compostos. Apesar de vários estudos de toxicidade de LIs em diferentes níveis de complexidade biológica, como é mostrado na figura 1, que incluem: enzimas, bactérias, algas, linhagens de células de ratos, células humanas, ervilhas d'água e invertebrados (PHAM et al., 2010), ainda não foi relatado nenhum estudo desses efeitos em células-tronco mesenquimais do cordão umbilical humano (CTMs). As CTMs podem ser definidas como células com grande capacidade de proliferação e auto-renovação, responsivas a estímulos externos e dar origem a diferentes linhagens celulares mais especializadas (ULLAH et al., 2015). Neste contexto, analisamos a influência dos LIs Cloreto de 1-etil-3-metilimidazólio (EMIM-Cl) e Cloreto de 1-butil-3metilimidazólio (BMIM-Cl) na viabilidade e na morfologia das CTMs.

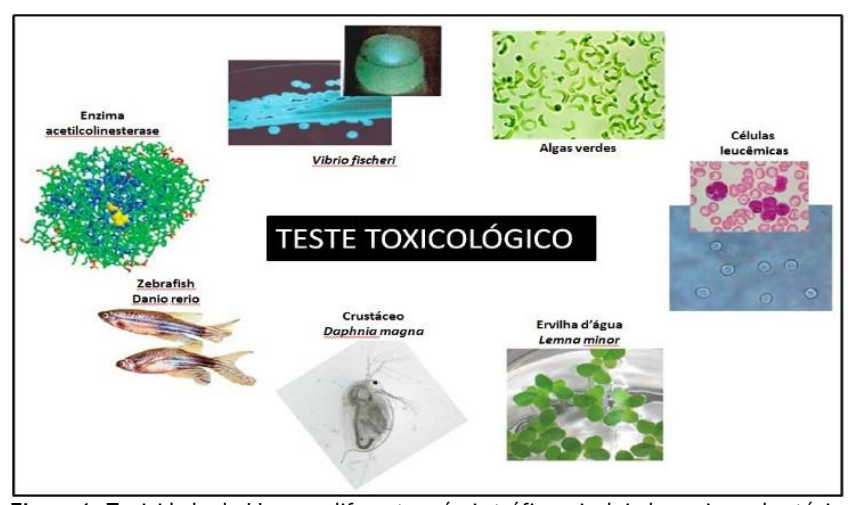

Figura 1. Toxicidade de Lls para diferentes níveis tróficos, incluindo enzimas, bactérias, algas verdes de água doce, células de mamíferos, ervilha d'água, crustáceos de água doce e zebrafish (Fonte: adaptado de PHAM et al, 2010).

\section{MATERIAIS E MÉTODOS}

Os cordões umbilicais foram doados voluntariamente por parturientes saudáveis, submetidas à cirurgia Cesariana no Hospital De Ávila (comitê de ética, protocolo 49503715.0.0000.5208). A obtenção das células foi realizada conforme a técnica da migração espontânea (MITCHELL et al., 2003; ISHIGE et al., 2009). As CTMs foram cultivadas em garrafas de cultura com meio Low DMEM (Gibco) suplementado com soro fetal bovino (SFB, Gibco), fator de crescimento (F12, Gibco) e antibióticos (penicilina e estreptomicina) em incubadora a $37^{\circ} \mathrm{C}, 80 \%$ de umidade e $5 \%$ de $\mathrm{CO}_{2}$. Todas as CTMs utilizadas estavam na segunda passagem. 0 teste de citotoxicidade foi realizado de acordo com a técnica colorimétrica do MTT (Brometo Tiazolil azul de Tetrazólio) (MOSMANN 1983). As CTMs foram distribuídas em placa de 96 poços com uma concentração de $1 \times 10^{4}$ células/poço. No grupo teste, as CTMs foram expostas ao EMIM-Cl ou BMIM-Cl, figura 2 (SigmaAldrich, USA) nas concentrações $(\mu M): 1 ; 10 ; 100 ; 300 ; 500 ; 1000$; 1500; 3000; 6000 e 10.000. Após 72 horas, foram adicionados $20 \mu \mathrm{L}$ do MTT $(5 \mathrm{mg} / \mathrm{mL})$, e a placa foi incubada por mais 4 horas. Para solubilização dos cristais de formazan, foram adicionados $100 \mu \mathrm{L}$ de dimetilsulfóxido (DMSO). As CTMs do grupo controle foram mantidas apenas em meio de cultura. As leituras da densidade ó ptica foram obtidas a $595 \mathrm{~nm}$ em espectrofotômetro (Varioskan, ThermoScientific, USA). A análise morfológica das CTMs realizou-se após 72 horas de sua exposição ao BMIM-Cl. As fotomicrografias foram obtidas por uma de câmera (MOTICAN2000, MOTIC, BR) acoplado à microscópio invertido (LEICA, DM IL, USA). Os dados estão apresentados como a média \pm desvio padrão de 6 experimentos. Utilizou-se análise de variância e o teste de Tukey para diferenciação entre grupos. 0 valor de $p<0,05$ foi considerado estatisticamente significativo.
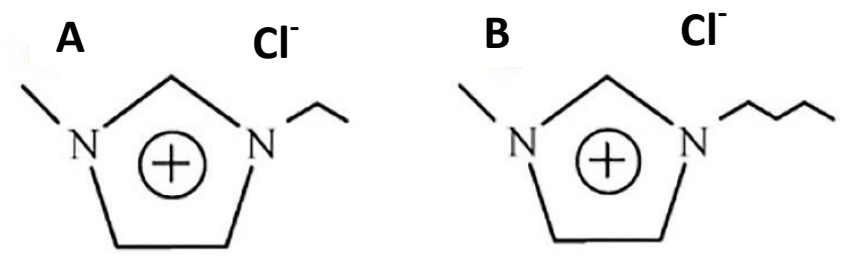

Figura 2. Estrutura química dos Lls. A. Estrutura catiônica dos sais orgânicos Cloreto de 1-etil-3-metilimidazólio (EMIM-Cl); B. Cloreto de 1-butil-3-metilimidazólio (BMIM-Cl). Ambos os compostos possuem o mesmo cátion, diferindo apenas na quantidade de carbonos presentes na cadeia lateral de posição 1 (Fonte: adaptado de CHEN, 2014). 


\section{RESULTADOS E DISCUSSÃO}

Na figura 3 é demonstrada a influência dos líquidos iônicos imidazó licos (EMIM-Cl e BMIM-Cl) na viabilidade das CTMs. Ambos os compostos influenciaram na viabilidade das CTMs (Figura 3A e 3B). Similarmente, estes líquidos também alteraram significativamente a viabilidade em células de carcinoma pulmonar (CHEN, 2014) e cé lulas Hela (STEPNOWSKI, 2004). Nota-se um fator de $15 \times$ do menor valor de concentração do $\mathrm{EMIM-Cl}$ em relação ao $\mathrm{BMIM}-\mathrm{Cl}$, no qual a viabilidade celular difere do controle (Figura $3 \mathrm{~A}$ e $3 \mathrm{~B}$ ). $O$ valor da concentração efetiva $\left(E C_{50}\right)$ foi de aproximadamente 29,00 $\pm 3,26$ $\mathrm{mM}$ no $\mathrm{EMIM}-\mathrm{Cl}$, e de $14,00 \pm 2,96 \mathrm{mM}$ no $\mathrm{BMIM}-\mathrm{Cl}$, portanto, a citotoxicicidade é dependente do tamanho da cadeia hidrofóbica dos Lls. O comprimento da cadeia lateral também influencia na citotoxicidade em outros tipos celulares, tais como: Células leucê micas (STOLTE et al, 2006); células HeLa (WANG et al., 2007); Carcinoma pulmonar (CHEN et al, 2014).

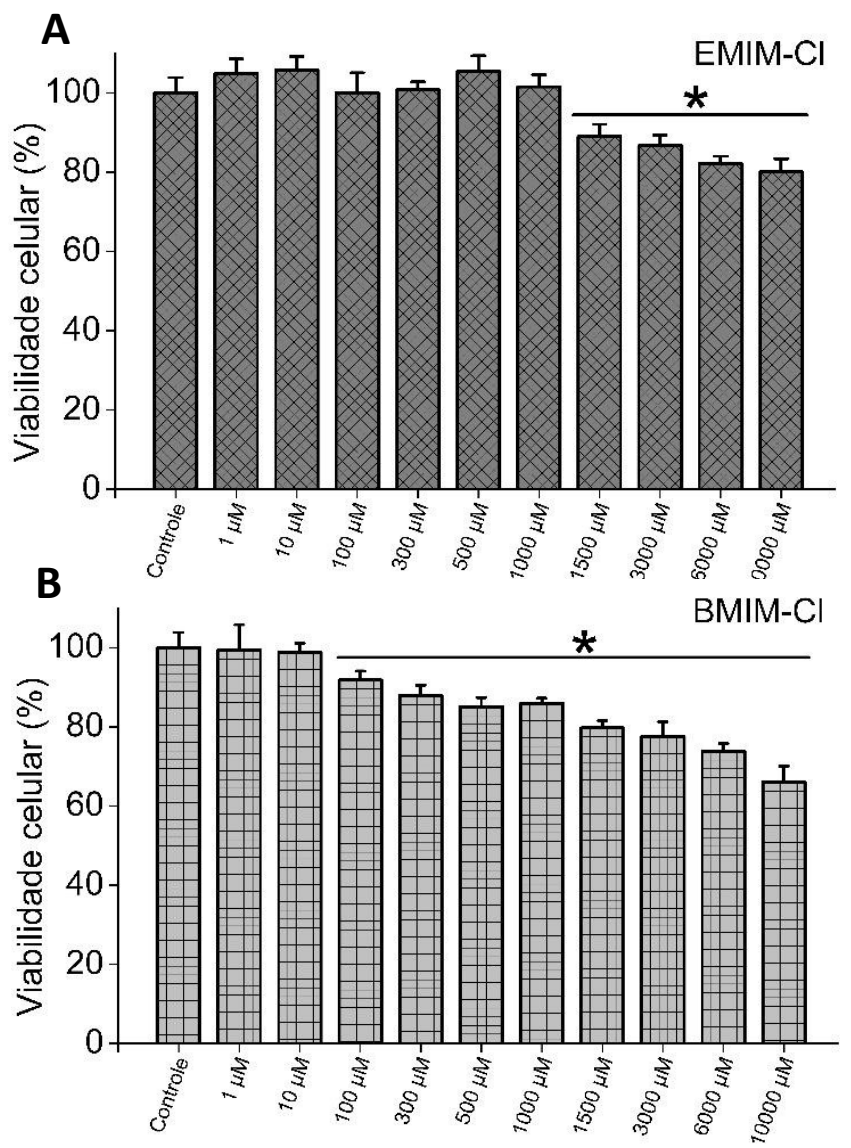

Figura 3. Citotoxicidade dos LIs nas CTMs. A. Efeito do EMIM-Cl na viabilidade das CTMs. B. Efeito do BMIM-Cl na viabilidade das CTMs. Os valores representam a média e desvio padrão de 6 experimentos independentes. Utilizou-se análise de variância e o teste de Tukey para diferenciação dos grupos. 0 valor de $p<0,05$ foi considerado significativo. $\left({ }^{*}\right)$ grupos, cujas as viabilidades diferem do grupo controle.

Devido a maior citotoxicidade do BMIM-Cl avaliou-se também a morfologia das CTMs (Figura 4). A figura 4a representa o grupo controle, ou seja, as CTMs não foram expostas ao $\mathrm{BMIM-Cl}$ e apresentaram-se com aspecto fibroblastóide. $\mathrm{Na}$ figura $4 \mathrm{~b}$, as CTMs expostas a menor concentração $(1 \mu \mathrm{M})$ do $\mathrm{BMIM}-\mathrm{Cl}$ mantiveram a mesma morfologia do grupo controle. O LI na concentração de 100 $\mu \mathrm{M}$ do $\mathrm{LI}$ induziu alterações morfológicas nas CTMs, com o surgimento de filamentos citoplasmáticos alongados e considerável espaçamento entre as células (Figura 4c). Nas maiores concentraçõ es do LI (Figuras 4d e 4e) as CTMs apresentaram diminuição de tamanho, perda de aderência e também foi observado presença de fragmentação celular. Estes aspectos são característicos de processo de apoptose (CHEN et al., 2014) ou de destruição direta da membrana plasmática (WANG et al., 2007).

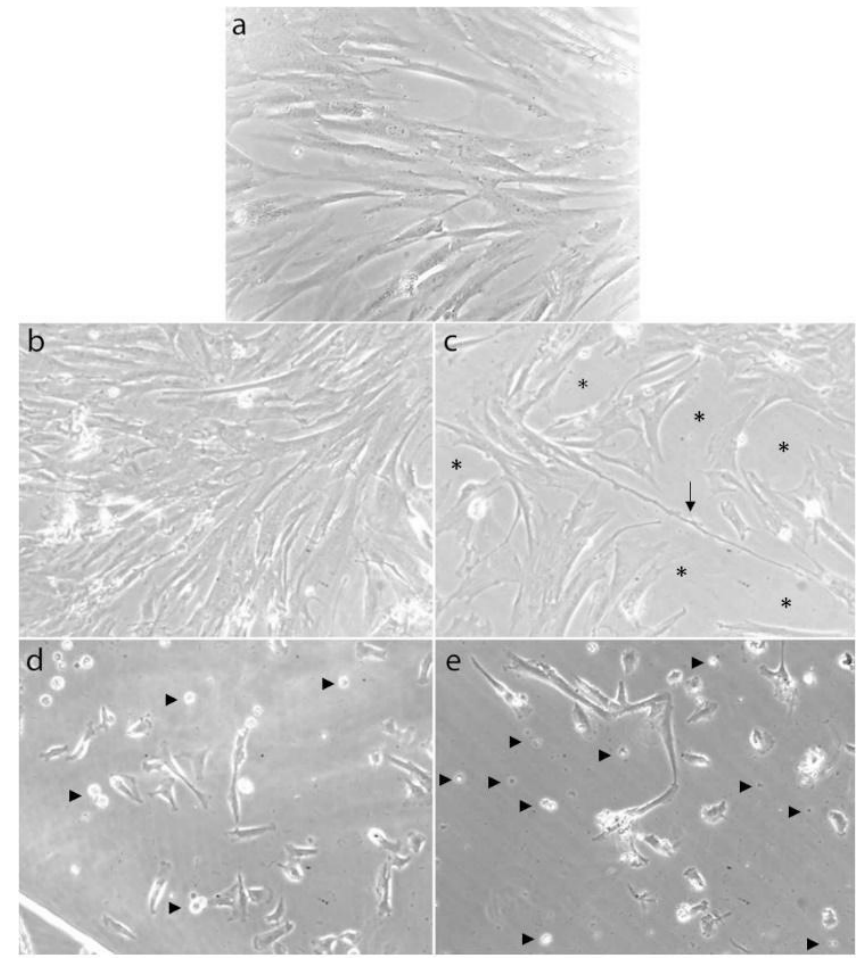

Figura 4. Fotomicrografias das CTMs expostas ao BMIM-Cl. a. Controle; b. CTMs expostas ao BMIM-Cl na concentração de $1 \mu \mathrm{M}$, apresentando morfologia conservada; c. $100 \mu \mathrm{M}$, presença de filamento citoplasmático (seta fina) e espaçamentos entre as células ( $\left.{ }^{*}\right)$; $\mathrm{d}$ e e (1000 e $10.000 \mu \mathrm{M}$, respectivamente) observam-se fragmentos celulares (cabeças de seta).

\section{CONCLUSÕES}

Nas células-tronco mesenquimais humanas o líquido iônico imidazó lico BMIM-Cl (Cloreto de 1-butil-3-metilimidazólio) é mais citotó xico que o EMIM-Cl (Cloreto de 1-butil-3-metilimidazólio) e causa alterações morfológicas.

\section{REFERÊNCIAS}

ANASTAS, P. T.; KIRCHHOFF, M. M. Origins, current status, and future challenges of Green Chemistry. Accounts of Chemical Research, v. 35, p. 686-694, 2002.

BATES, E. B. et al. $\mathrm{CO}_{2}$ Capture by a Task-Specific lonic Liquid. Chemical Society, v. 124, p. 926-927, 2002.

CHEN, H. L. et al. Cytotoxicity of Imidazole Ionic Liquids in Human Lung Carcinoma A549 Cell Line. Journal of the Chinese Chemical Society, v. 61. p. 763-769, 2014.

CVJETKO, M. et al. Cytotoxic effects of imidazolium ionic liquids on fish and human cell lines. Archives of Industrial Hygiene $e$ Toxicology, v. 63, p. 15-20, 2012.

ISHIGE, I. et al. Comparison of mesenchymal stem cells derived from arterial, venous, and Wharton's jelly explants of human umbilical cord. International Journal of Hematology, v. 90, p. 261-269, 2009.

JING, B. et al. Interaction of Ionic Liquids with a Lipid Bilayer: A Biophysical Study of Ionic Liquid Cytotoxicity. The Journal of Physical Chemistry, v. 120, p. 2781-2789, 2016.

MITCHELL, K. E. et al. Matrix cells from Wharton's jelly form neurons and glia. Stem cells, v. 21, p. 50-60, 2003.

MOSMANN, T. Rapid Colorimetric Assay for Cellular Growth and Survival: Application to Proliferation and Cytotoxicity Assays. Journal of Immunological Methods, v. 65, p. 55-63, 1983.

PHAM, T. P. T.; CHO, C. W.; YUN, Y. S. Environmental fate and toxicity of ionic liquids: A review. Water Research, v. 44, p. 352372, 2010. 
PLECHKOVA, N. V.; SEDDON, K. R. Applications of ionic liquids in the chemical industry. Chemical Society Reviews, v.37, p. 123150, 2008.

STEPNOWSKI, P. et al. Evaluating the cytotoxicity of ionic liquids using human cell line HeLa. Human \& Experimental Toxicology, v. 23. p. 513-517, 2004.

STOLTE, S. et al. Anion effects on the cytotoxicity of ionic liquids. Green Chemistry, v. 8, p. 621-629, 2006.

ULLAH, I.; SUBBARAO, R. B.; RHO, G. J. Human mesenchymal stem cells - current trends and future prospective. Bioscience Reports, v. 35, p. 1-18, 2015.

WANG, $X$. et al. Cytotoxicity of ionic liquids and precursor compounds towards human cell line HeLa. Green Chemistry, v. 9, p. 1191-1197, 2007. 